\title{
Why drivers are frustrated: results from a diary study and focus groups
}

\author{
Esther Bosch ${ }^{*}$ D, Klas Ihme, Uwe Drewitz, Meike Jipp and Michael Oehl
}

\begin{abstract}
Introduction: Designing emotion-aware systems has become a manageable aim through recent developments in computer vision and machine learning. In the context of driver behaviour, especially negative emotions like frustration have shifted into the focus of major car manufacturers. Recognition and mitigation of the same could lead to safer roads in manual and more comfort in automated driving. While frustration recognition and also general mitigation methods have been previously researched, the knowledge of reasons for frustration is necessary to offer targeted solutions for frustration mitigation. However, up to the present day, systematic investigations about reasons for frustration behind the wheel are lacking.

Methods: Therefore, in this work a combination of diary study and user focus groups was employed to shed light on reasons why humans become frustrated during driving. In addition, participants of the focus groups were asked for their usual coping methods with frustrating situations.

Results: It was revealed that the main reasons for frustration in driving are related to traffic, in-car reasons, selfinflicted causes, and weather. Coping strategies that drivers use in everyday life include cursing, distraction by media and thinking about something else, amongst others. This knowledge will help to design a frustration-aware system that monitors the driver's environment according to the spectrum of frustration causes found in the research presented here.
\end{abstract}

Keywords: Emotion-aware systems, Frustration, Emotions in driving

\section{Introduction}

When watching car advertisements, we see empty roads, happy faces, relaxed people, and children enjoying their rides. When comparing this to what we experience every day on the road, reality looks different: We get up too late, rush to work, and get annoyed about slow vehicles in front of us while crying children on the back seat take our last hope of a relaxed start into the day. This is one out of endless examples that may result in an emotion that can crucially influence driver's focus of attention and also wellbeing: frustration. Frustration is defined as the emotion that occurs when a goal is blocked to be reached $[5,15]$. It is to be differentiated from anger, which is directed towards someone that is responsible for an undesirable event [28].

\section{* Correspondence: esther.bosch@dlr.de}

German Aerospace Center (DLR), Institute of Transportation Systems, Lilienthalplatz 7, 38108 Braunschweig, Germany
As stated in the frustration-aggression-hypothesis, frustration is the emotion that often precedes anger and aggression (cf. $[3,5,21]$ ). Previous research clearly shows the impact that frustration has on driver behaviour and attention. However, to the best of our knowledge, no study systematically has investigated frustrating events during driving and their relative amount of occurrence yet. Hence, this work aims to shed light on the spectrum of reasons for which drivers become frustrated, based on subjective reports of the same. In order to study this, the two complementary methods of a diary study (showing how often which frustrating situation occurs within a given time) and focus groups (showing which frustrating events mainly stay in memory) were employed. In the focus group study, we additionally investigated user's daily coping strategies with frustrating situations on the road.
Springer Open

(C) The Author(s). 2020 Open Access This article is licensed under a Creative Commons Attribution 4.0 International License, which permits use, sharing, adaptation, distribution and reproduction in any medium or format, as long as you give appropriate credit to the original author(s) and the source, provide a link to the Creative Commons licence, and indicate if changes were made. The images or other third party material in this article are included in the article's Creative Commons licence, unless indicated otherwise in a credit line to the material. If material is not included in the article's Creative Commons licence and your intended use is not permitted by statutory regulation or exceeds the permitted use, you will need to obtain permission directly from the copyright holder. To view a copy of this licence, visit http://creativecommons.org/licenses/by/4.0/. 


\section{Previous work}

\subsection{Frustration during driving}

Frustration in driving is critical in manual as well as automated driving. In manual driving, frustrated drivers were less aware of potential distractions, their mental state, and potential dangers in the driving environment [16]. Earlier research has shown that frustrated drivers exhibit more aggressive driving styles [4, 12, 25]. In automated driving, frustration might turn out as a central challenge: every user of modern complex interfaces knows how frustrating it can be to try to use an interface that does not behave as expected [14]. Therefore, even during automated driving frustration can occur and may decline acceptance and comfort. In conclusion, frustration is an emotion that can strongly affect road safety, user experience and comfort in manual and automated driving.

\subsection{Frustration-aware systems}

The concept of designing frustration-aware systems has emerged due to the above mentioned effects of frustration on user experience and road safety [18, 22]. The aim of such a system would be recognition of frustration and successful mitigation of the same. Three main steps are necessary to design such a system: 1) recognizing that a driver or passenger is frustrated, e.g. by means of physiological measurements or video recordings, 2) detecting the reason for frustration and 3) offering help that is tailored towards the specific situation. Several researchers investigated the first step of recognizing frustration [1, 11, 19] and the third step of mitigating frustration (e.g., [6, 13]), but the intermediate step of detecting its reasons remains elusive [17]. In addition, knowledge of these environmental factors can crucially improve the first step of detecting frustration [19]. As a prerequisite for this step, knowledge of the frustrationinducing events' spectrum is required. Therefore, on the way towards designing frustration aware-systems it is a necessary step to gain insight into reasons for which people get frustrated in the vehicle. With increasing automation accompanied by developments in driver monitoring, the extent of available sensor technology in modern vehicles is growing. This is an advantage for recognizing not only frustration itself, but also reasons for the same - inside and outside the vehicle. By understanding the spectrum of reasons for frustration, a frustration-aware system can be equipped with the knowledge of which information is relevant to scan in order to recognize sources of frustration.

\subsection{Coping strategies}

The last step of designing a frustration-aware system is to offer help that is specifically tailored towards the situation at hand. To do so in a user-centred way, investigation of user's everyday coping strategies with frustrating in-car situations is of interest. Various strategies for coping with negative emotions like frustration have been proposed previously [7, 20]. One example is Gross [9], who suggests to differentiate coping strategies into the categories of attentional deployment, response modulation, cognitive change, situation modification and situation selection. Situation selection is described as 'approaching or avoiding certain people, places, or objects in order to regulate emotions'. This is close to situation modification, which are 'active efforts to directly modify the situation so as to alter its emotion impact'. Attentional deployment describes the process of directing attention towards or away from an emotional situation, e.g., looking for distraction. Cognitive change is defined as changing the cognitive steps necessary to elicit an emotion. Response modulation aims to modify the response to an emotion after it is already fully felt. While coping strategies have been widely studied, no research so far has investigated which coping strategies are used in frustrating in-car situations in everyday life.

\subsection{Methods to investigate causes for emotions}

Focus groups and diary studies are two common methods of psychological qualitative analysis [2, 8, 24]. An advantage of diary studies is that participants can report about their feelings during everyday situations in real-time. Bias of emotion cause or intensity due to memory is very unlikely. The benefit of a focus group study is that in-depth discussion lead to reflection on emotion causes and intensity. In comparison, the diary study is likely to reflect the amount of day-to-day occurrences of frustration. In contrast to that, the focus group study reveals which frustrating situations stay in memory on the long term. Both methods have been used previously to investigate emotions on in the road. Underwood et al. [27] used a diary study in which participants wrote down situations in which they felt anger over a period of two weeks. The participants reported situations after each car journey they took with help of a microcassette recorder and also rated their anger on a Likert scale. Huemer et al., [10] used focus groups to identify anger provoking events in cycling. They validated these findings by using a diary study. A common timeframe often used for diary studies is one week [2, 24]. Similarly, the research presented here has used a one week - diary study to investigate the spectrum and frequency of frustrating driving situations, and a focus group study to identify these situations in-depth and with a focus on long-term remembered frustrating situations.

\section{Diary study}

This study set out to explore reasons of frustration by means of a diary study. By collecting data for one week 
after every car ride, real-life occurring frustrating situations were captured together with their frequency.

\subsection{Methods}

Diary data was acquired in February 2019 using paper questionnaires which were distributed among the authors' networks. The participants were asked to fill out the questionnaire at the end of each car drive for seven days in a row to report their daily frustration experiences during driving.

\subsubsection{Participants}

Of 80 questionnaires that were distributed, 51 Germanspeaking participants (22 women, three unspecified gender) returned the questionnaire. The participants' age range was 20 to 73 years with a mean of 40.9 years (standard deviation $[\mathrm{SD}]=12.5$ years). On average, they drove $17,054 \mathrm{~km}$ per year $(S D=11,845 \mathrm{~km})$, and had their driving license for 24 years $(\mathrm{SD}=12.5$ years). Figure 1 shows the distributions of demographic data.

\subsubsection{Questionnaire}

The German paper questionnaire for the diary study was custom-designed for the study and had fourteen pages. The first page contained the declaration of consent. On page two, the questionnaire's aim was explained and it was clarified that situations that cause frustration can occur before and during the ride. The definition of frustration was given as 'emotion that arises through a goal that is blocked to be reached.' For each frustrating situation that occurred to them during the week of data acquisition, participants were asked to fill in frustration intensity, a short description of the frustrating situation, and the importance of the blocked goal. Frustration intensity and the importance of the blocked goal were rated on a 5-point Likert-scale (from $1=$ 'not at all', 'a little bit', 'somewhat', 'very' to $5=$ 'extremely').

On page two and three, four examples of how to fill in the questionnaire were given (for example, 'I wanted to check the weather on my smartphone but the browser crashed all the time' as very frustrating and a little bit important goal).

On page four, participants were asked to provide personal information (age, gender, $\mathrm{km} / \mathrm{year}$, year of driver's license acquisition).

On pages five to twelve, participants were asked to report frustrating situations, the level of frustration intensity and the importance of the goal.

On page 13, it was asked on how many days of the week they drove and how often they remembered to fill in the questionnaire.

On the last page, the participants were asked to recall a maximum of three previous frustrating situations in driving that they experienced before the diary study.

\subsubsection{Data analyses}

For data analyses, the paper questionnaires were transliterated and three independent raters decided whether or not the reported situations described the emotion of frustration according to the definition of the feeling that arises when a goal is blocked to be reached [28]. The three raters also decided on categories for reasons for frustration with an inter-rater-reliability of $99.1 \%$. In case of disagreement they solved the disagreement by discussion and agreed on a category together.

Subsequently, the correlation between the importance of the goal and frustration intensity was calculated. Data was separated between situations that happened during the week of data acquisition (pages five to twelve of the questionnaire) and recalled situations (page 14 of the questionnaire). In the following, the amount each category was mentioned was counted, and the mean frustration intensity per category was calculated in R ( $\mathrm{R}$ Core [26]).

\subsection{Results}

The participants drove on 6.2 days out of seven on average and remembered to fill in the questionnaire on 5.9 out of seven days. 346 situations were described in total, out of which 88 situations were recalled, i.e., from their previous driving history. The raters excluded 161 situations because they described emotions other than frustration. The raters
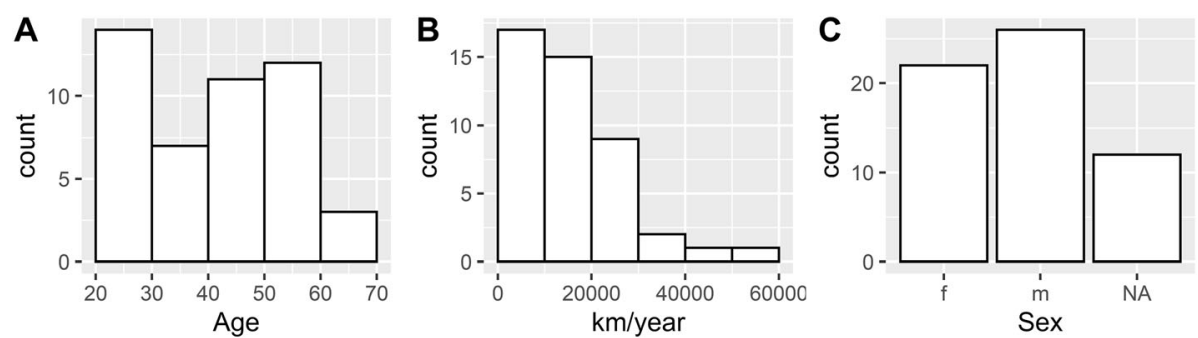

Fig. 1 Demographic data of participants. a Age distribution, b mileage distribution, c Sex distribution (NA for participants who did not identify their gender) 


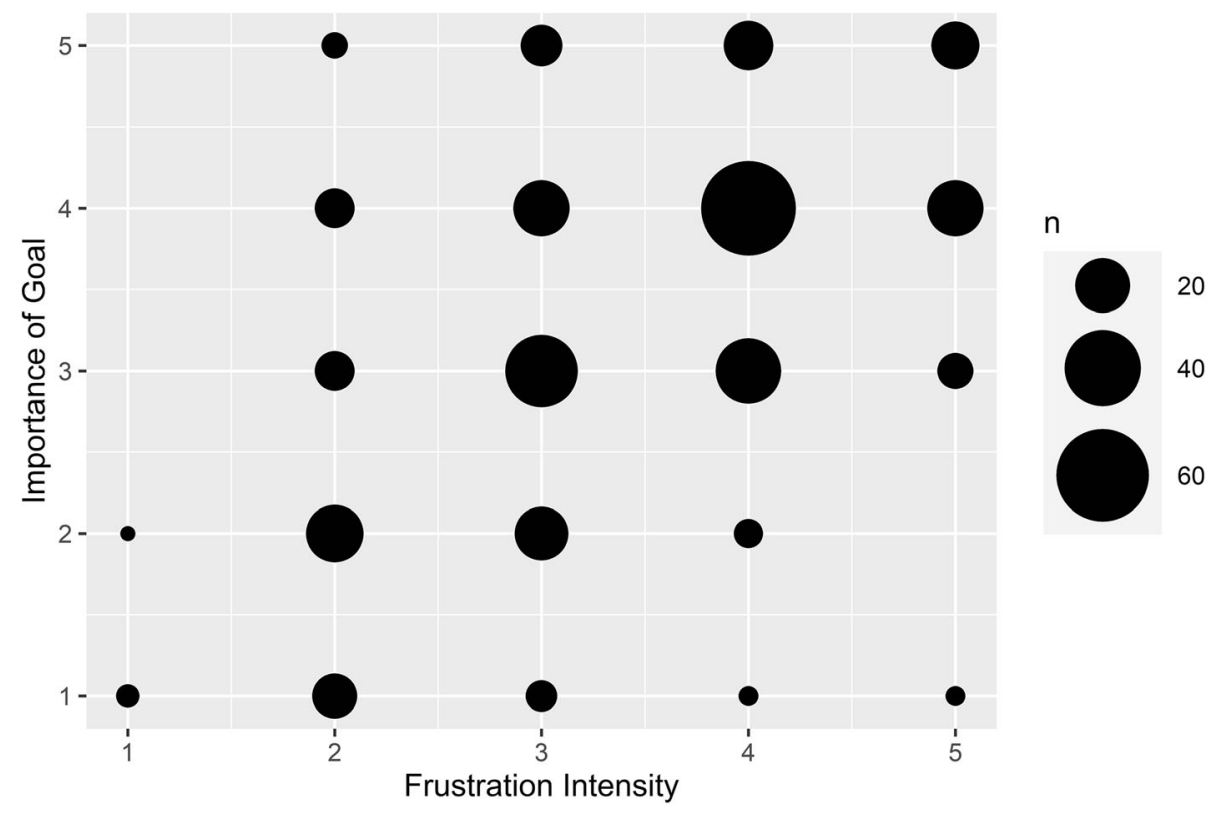

Fig. 2 Bubble plot that shows the correlation of importance of goal and frustration intensity. $\mathrm{n}$ is the amount of described situations

considered 136 out of the 161 situations as 'anger'. The other situations were rated as shame (6 situations), fear (3 situations), scare (2 situations), overextension (2 situations), disgust (1 situation), sadness (1 situation), worry (1 situation). Consequently, 185 frustrating situations were available for analyses. These situations happened in 128 drives, which results on average in 1.44 situations per drive. The categories and their respective subcategories for both the diary study and the focus group study were:

\begin{tabular}{ll}
\hline Category & Subcategory \\
\hline Traffic & Finding parking \\
& Dense traffic \\
In-car situations & Other passengers/social environment \\
& Human Machine Interface \\
& Technical defects \\
& Events before the start of ride \\
Weather & - \\
Self-inflicted & - \\
Other & - \\
\hline
\end{tabular}

A Spearman's correlation between the importance of the blocked goal and frustration intensity resulted in a rho of .48, $p<.001$ (Fig. 2). In this figure, a perfect correlation would show only large bubbles on the diagonal line between 'Frustration Intensity' and 'Importance of Goal'. Also, the bigger bubbles on the right-hand side of the plot indicate that generally more situations have been rated with a high frustration rating.

The reasons for frustration were categorized into four categories and eight subcategories. Categories, subcategories and examples of each can be found in Table 1, the amount each category was mentioned in Fig. 3 (situations that occurred during the week of data acquisition) and Fig. 4 (recalled situations). For situations that occurred during the week of data acquisition, most situations were sorted into the category 'traffic' (54.5\%), which consisted of the subcategories dense traffic (31.3\%), red lights (9\%), finding parking (7.5\%), construction sites (4.5\%), unnecessary traffic rules (1.5\%) and unclear traffic management $(0.7 \%)$. The category that occurred secondmost was in-car situations (16.4\%) which consisted of the subcategories social environment (6.7\%), HumanMachine-Interface (3\%), technical defects (3\%), events before the start of ride (3\%) and wrong information about traffic $(0.7 \%)$.The third category was weather (13.4\%), which did not have a subcategory. The smallest category with $9.7 \%$ and no subcategories was the selfinflicted category. Interestingly, the amounts these categories were mentioned are very similar for the recalled situations (Fig. 4). The intensity ratings for each subcategory do not show any clear differences between subcategories and are shown in Fig. 5 (situations during the week of data acquisition) and Fig. 6 (recalled situations). 
Table 1 Frustrating situations sorted by categories and subcategories with examples

\begin{tabular}{|c|c|c|}
\hline Category & Subcategory & Example \\
\hline \multicolumn{3}{|l|}{ Traffic } \\
\hline & \multirow[t]{2}{*}{ Finding parking } & ,no free parking spots' \\
\hline & & ,my usual parking spot was taken' \\
\hline & \multirow[t]{2}{*}{ Dense traffic } & I had to wait for two red light cycles' \\
\hline & & ,standing three hours because of traffic jam' \\
\hline & \multirow[t]{2}{*}{ Red lights } & , had to wait for 9 min at a closed train gate' \\
\hline & & ,many red lights and high traffic density' \\
\hline & \multirow[t]{2}{*}{ Construction sites } & ,roadworks and road constriction' \\
\hline & & ,long roadworks with speed limits' \\
\hline & Unclear traffic management & ,missing lane change from the center lane to the left lane' \\
\hline & Unnecessary traffic rules & ,many trucks and speed limits for no clear reason' \\
\hline \multicolumn{3}{|l|}{ in-car } \\
\hline & \multirow[t]{2}{*}{ Human-Machine-Interface } & ,setting up the navigation system was so complicated I had to stop on the right hand side' \\
\hline & & $\begin{array}{l}\text {,Android Auto updated, all settings were changed. I had to leave the highway and change back all } \\
\text { settings' }\end{array}$ \\
\hline & \multirow[t]{2}{*}{ Events before start of ride } & ,co-driver complains about driving style' \\
\hline & & ,badly cognizable pedestrian because of bad weather conditions' \\
\hline & \multirow[t]{2}{*}{ Social environment } & ,argument with my son' \\
\hline & & ,car passengers linger at the roadhouse' \\
\hline & \multirow[t]{2}{*}{ Technical defect } & ,breakdown of the car, damaged beyond repair' \\
\hline & & ,flat tire on the highway' \\
\hline & $\begin{array}{l}\text { Wrong information about } \\
\text { traffic }\end{array}$ & ,Route diversion isn't displayed in the navigation system' \\
\hline \multicolumn{3}{|c|}{ self-inflicted } \\
\hline & & ,forgot my chip-card to get into the parking garage' \\
\hline & & I got caught in a speed trap' \\
\hline \multicolumn{3}{|c|}{ weather conditions } \\
\hline & & "Having to drive slowly because of snow' \\
\hline & & "bad sight because of blinding lights of oncoming vehicles in the snow' \\
\hline \multicolumn{3}{|l|}{ others } \\
\hline & & ,something clatters in the trunk' \\
\hline & & ,only bad music in the radio and everywhere the same music' \\
\hline
\end{tabular}

\section{Focus group study}

\subsection{Aim}

The focus group study was conducted to further investigate reasons for which drivers become frustrated. In comparison to a diary study, focus groups enable discussions between participants, and make it possible to remind participants to stay with situations that are suitable according to our definition of frustration [23]. In addition to finding out reasons for frustration, the focus groups were designed to find out methods to cope with frustrating situations.

\subsection{Methods}

Seven focus groups consisting of four to six people each were conducted in July 2019. The participants were drawn from the Institute's participant data base.

\subsubsection{Participants}

In total, 37 participants (14 women) participated. The mean age was 48.4 years with a range from 19 to 74 years $(S D=20.0$ years $)$. The distribution of participants' demographic data is shown in Fig. 7. They gave their written informed consent, were native German speakers and had a valid driver's license. 


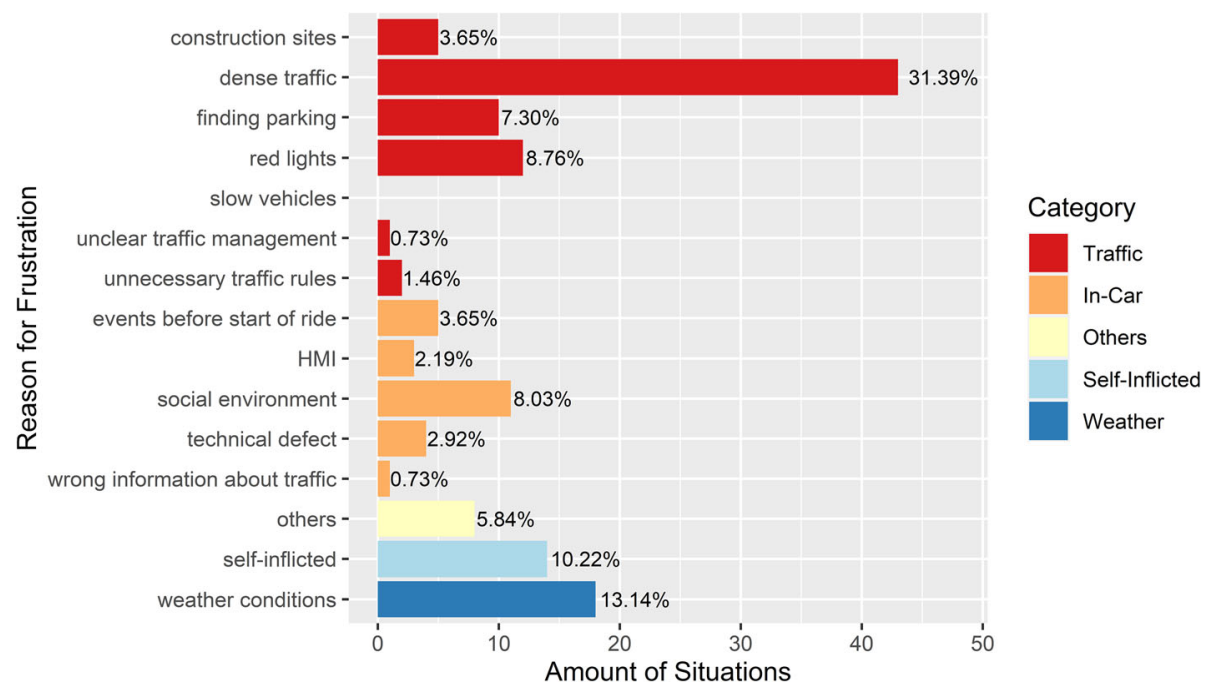

Fig. 3 Amount of frustrating situations that occurred during the week of the diary study. Categories from both the diary study and the focus group study are shown on the $y$-axis for comparison

\subsubsection{Procedure}

Two female moderators lead the focus groups. Each session started with an explanation of the definition of frustration, especially in distinction to anger. In the following, the participants had time to brainstorm frustrating moments that they had experienced during driving. The results were collected on a pin board. Double mentions were kept, too. For each situation, a rating on the frustration intensity was given on a scale from one to five by the person who brainstormed the situation. Subsequently, the participants indicated how they usually cope with their frustration in the given moment. Each focus group took about $2 \mathrm{~h}$.

\subsubsection{Data analyses}

The focus groups' data (audio recordings and photo protocols) were transliterated and frustration situations and coping strategies were categorized (inter-raterreliability: 95.9\%). For the 19 cases that they disagreed, a third rater gave a category and the majority vote won. Frustrating events were categorized into the same categories and subcategories as for the diary study. Also coping strategies were categorized into subcategories and categories. Categories were chosen according to Gross [9]. In his work, Gross divided emotion regulation into the categories of situation selection (for example, avoiding places/people that cause an emotion), situation modification (i.e., changing the situation to change the emotion it elicits), attentional deployment (like distraction), cognitive change (like reevaluation of the situation) and response modulation (e.g. taking a deep breath to calm down). Subsequently, the amount categories were mentioned was counted and their mean frustration intensity or helpfulness rating calculated.

\subsection{Results}

\subsubsection{Frustrating events}

In total, 107 frustrating situations and 116 coping strategies were collected. The category that was mentioned most often was traffic (63.3\%). Other categories included in-car causes for frustration like other passengers or the Human-Machine-Interface (13.1\%), self-inflicted causes like starting too late (11.2\%) and weather conditions (e.g., bad sight because of snow [7.5\%]). These four high-level categories were divided into 13 subcategories (Fig. 8 for amounts and Fig. 9 for frustration intensity). Examples of situations with their categories and subcategories can be found in Table 2, the amount that each category was mentioned in Fig. 8.

The situations that were with more than $5 \%$ difference mentioned more often in the diary study (excluding recalled situations) were 1) dense traffic (31.3\% vs. $16.8 \%), 2)$ social environment (6.7\% vs. $1.9 \%)$, and 3$)$ weather conditions $(13.4 \%$ vs. $7.5 \%)$. The situations that were with more than $5 \%$ mentioned more often in the focus group study were slow vehicles $(6.5 \%$ vs. 0$)$, unclear traffic management $(8.4 \%$ vs. $0.7 \%)$ and unnecessary traffic rules (6.5\% vs. $1.5 \%)$.

\subsubsection{Frustration intensity}

Descriptive statistics indicate that frustration was highest for 'HMI' and 'wrong information about traffic' and lowest for 'weather conditions' and 'others' (Fig. 9). 


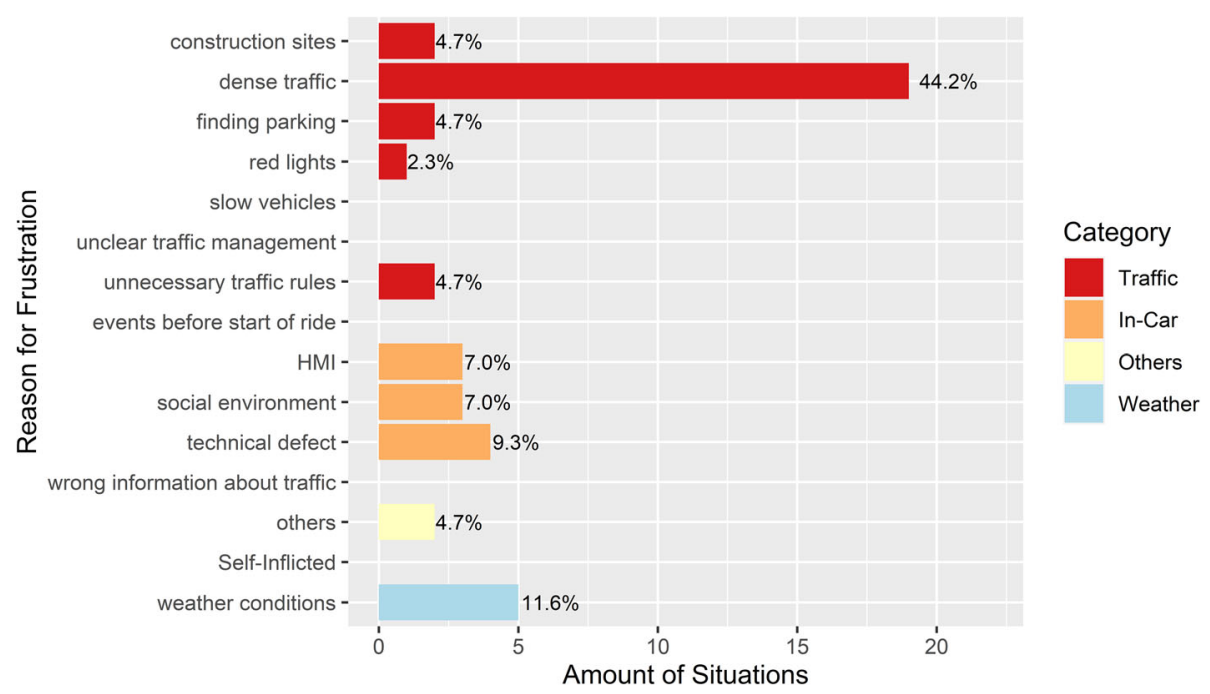

Fig. 4 Amount of recalled frustrating situations

\subsubsection{Coping strategies}

Participants described their usual coping strategies with frustrating situations (Table 3 and Fig. 10) and how helpful they evaluate them (Fig. 11). According to the coping strategies proposed by Gross, [9], 35 coping strategies mentioned were categorized as attentional deployment, 32 as response modulation, 21 as cognitive change, 17 as situation modification and 11 as situation selection. In the subcategories, the strategy mentioned the most was cursing (18.3\%), followed by distraction by media (17.4\%), thinking about something else (11.3\%), prevention strategies (9.6\%), thinking differently about the situation (7.8\%), breathing or relaxing $(7 \%)$, accepting the situation $(6.1 \%)$, adapting one's own driving style (6.1\%), looking for a solution $(5.2 \%)$, leaving the situation or taking a break $(3.5 \%)$, distraction by others (2.6\%), talking to someone about the situation (2.6\%), changing one's aims (1.7\%) and smoking (0.9\%).

\section{Discussion}

This study was designed to determine the spectrum of reasons for frustration in driving and possible mitigation methods for the same. For this, the two methods of a diary study and a focus group study were employed. In comparison, the diary study reveals more information about day-to-day occurrences of frustration. In contrast,

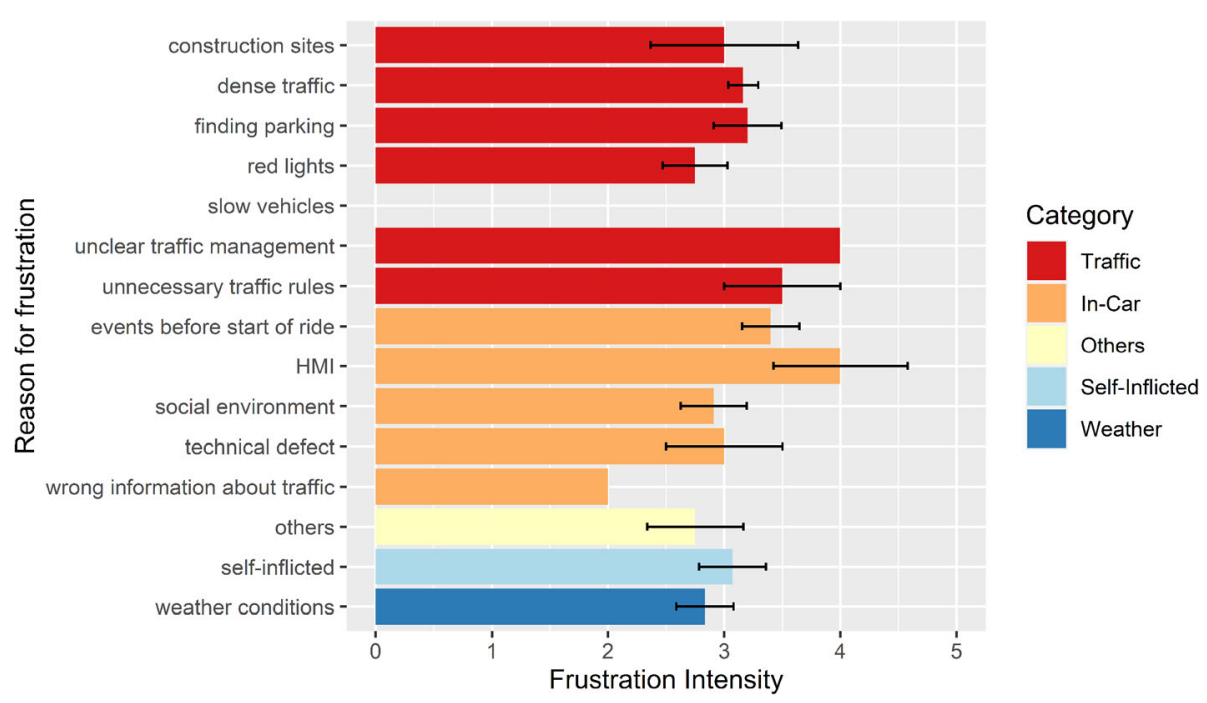

Fig. 5 Frustration intensity sorted by category. Error bars indicate standard error of the mean 


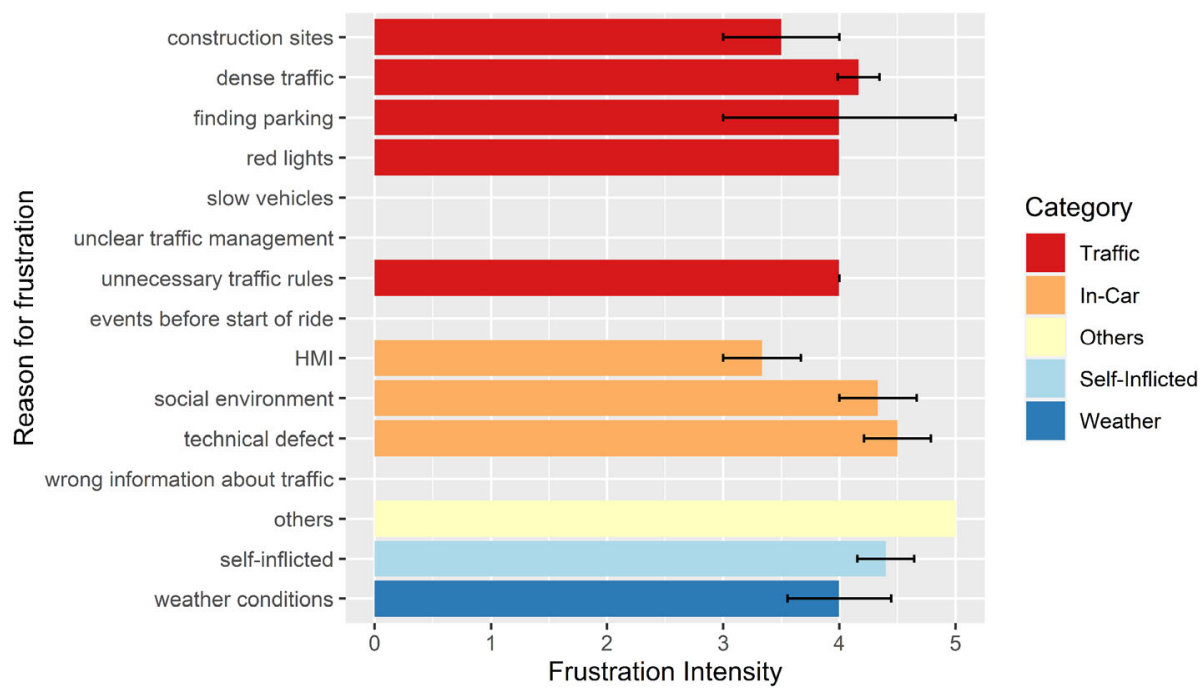

Fig. 6 Frustration intensity of recalled situations, sorted by category. Error bars indicate standard error of the mean

the focus group study explored which reasons for frustration stay in memory on the long term.

\subsection{Reasons for frustration}

The high correlation between frustration intensity and importance of the goal supports the definition of frustration as the emotion that arises when a goal is blocked to be met [28]. Furthermore, the situations that lead to frustration during driving were collected and their frequency counted: traffic (diary: $54.5 \%$, focus groups: $63.3 \%$ ), in-car (diary: $16.4 \%$, focus groups: 13.1\%), self-inflicted (diary: 9.7\%, focus groups: 11.2\%), weather (diary: $13.4 \%$, focus groups: $7.5 \%$ ) and others (diary: $6.0 \%$, focus groups: $4.7 \%$ ). Interestingly, some differences in the results from the two employed methodological approaches occurred. Especially the subcategories of dense traffic, social environment and weather conditions seem to occur more often in day-today-life than they are remembered. Vice versa, situations that are more often named from memory than they occur in everyday life are slow vehicles, unclear traffic management and unnecessary traffic rules. These differences might be due to the fact that some situations are frustrating in the moment but less remembered on the long term. This might have various reasons. For example, users might show increased acceptance for frustrating events to which they can relate better or the reasons of which they understand better. By this, situations that are frustrating in a situation might be remembered less on the long term (dense traffic, social environment and weather conditions). On the other hand, if reasons are unclear, frustrating situations are increasingly remembered on the long term (slow vehicles, unclear traffic management and unnecessary traffic rules).

Unfortunately, this study could only assess frustrating situations and coping methods in manual driving. For automated driving, especially the cases mentioned in the in-car category would most likely be of interest. Most of these in-car situations could occur as likely or even more likely in automated driving. In a study with a similar goal - finding emotional triggers during a $50 \mathrm{~min}$
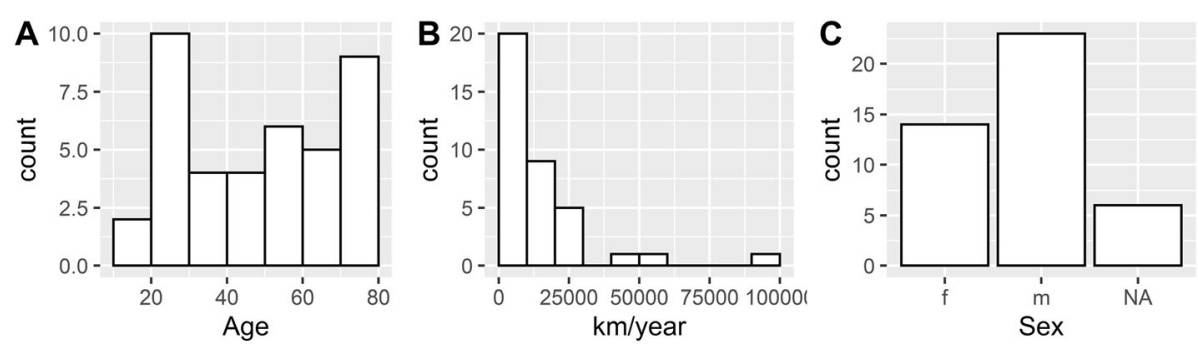

Fig. 7 Demographic data of participants. a Age distribution, b Mileage distribution, c Sex distribution (NA for participants who did not identify their gender) 


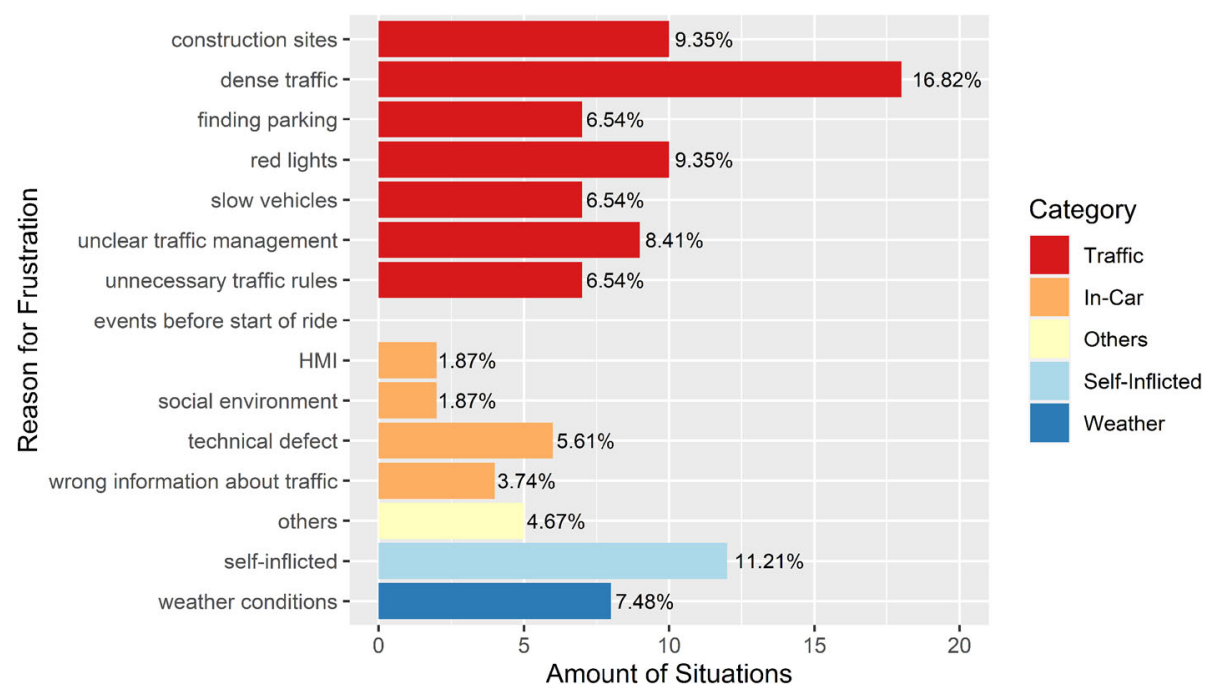

Fig. 8 Amount that each subcategory was mentioned in the focus groups

car drive - [29] found that traffic, driving task, HumanMachine-Interface, and navigation most frequently lead to negative emotions. This is in line with our findings. To sum up, situations that lead to frustration most frequently were related to traffic, in-car situations and self-inflicted causes.

\subsection{Coping with frustration}

Of Gross' [9] categories, attentional deployment (distraction, thinking about something else) and response modulation (cursing, breathing/relaxing) were mentioned as being used most often. In contrast to this, the categories of situation selection (prevention strategies) and situation modification (looking for a solution) were rated as most helpful. As a concrete example, when asking participants about their own coping strategies, 'cursing' was mentioned the most often and rated as least helpful on average. A strategy that was rated as very helpful but only six times mentioned as actually used is look for a solution'. This is an important gap giving room for effective intervention.

For a frustration-aware system, this could mean that after having recognized frustration and its cause, methods of distraction or a voice assistant helping with modification of the emotional response are most interesting to develop. The exact character of the same is a promising next step for further research.

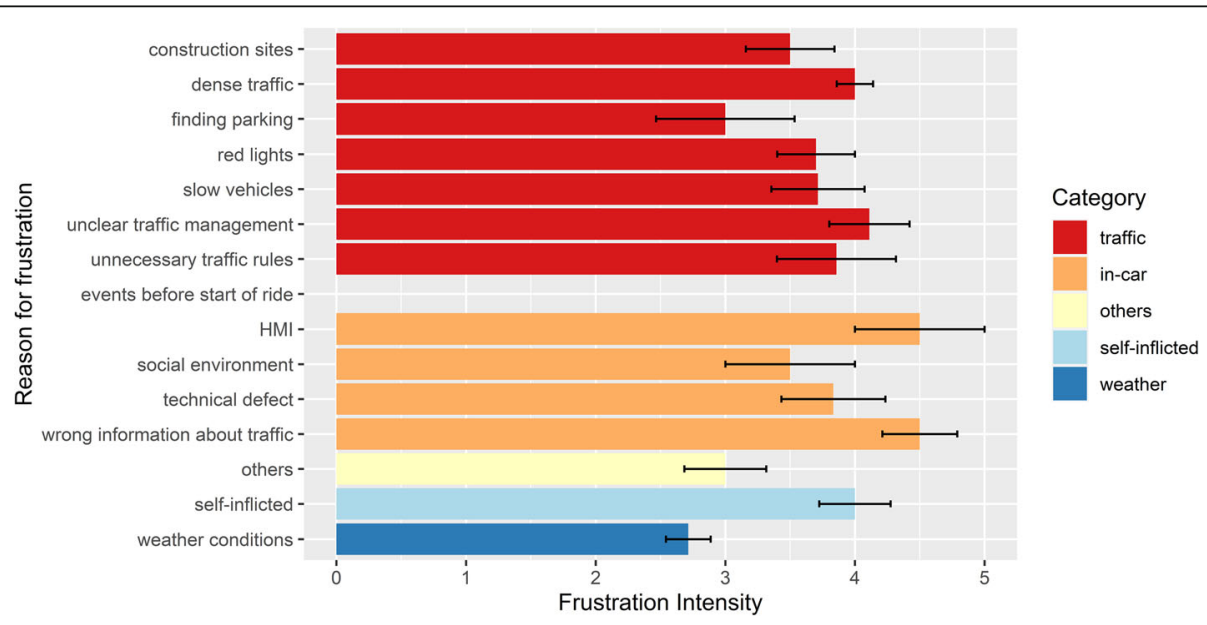

Fig. 9 Frustration intensity sorted by subcategories. Error bars indicate standard error of the mean 
Table 2 Frustrating situations sorted by categories and subcategories with examples

\begin{tabular}{|c|c|c|}
\hline Category & Subcategory & Example \\
\hline \multicolumn{3}{|l|}{ traffic } \\
\hline & \multirow[t]{2}{*}{ Construction sites } & 'roadworks' \\
\hline & & 'track width of roadworks' \\
\hline & \multirow[t]{2}{*}{ Dense traffic } & 'traffic jam due to an accident' \\
\hline & & 'slow traffic flow in the rush hour' \\
\hline & \multirow[t]{2}{*}{ Finding parking } & 'didn't find a parking spot' \\
\hline & & 'parking in big cities' \\
\hline & \multirow[t]{2}{*}{ Red lights } & 'bad traffic light circuit' \\
\hline & & 'no green wave on the main street' \\
\hline & \multirow[t]{2}{*}{ Slow vehicles } & 'stuck behind a truck on a curvy road' \\
\hline & & 'slow car on the road' \\
\hline & \multirow[t]{2}{*}{ Unclear traffic management } & 'too many road signs' \\
\hline & & 'badly signposted diversion road' \\
\hline & \multirow[t]{2}{*}{ Unnecessary traffic rules } & 'unnecessary speed limit' \\
\hline & & 'traffic light circuit led to a long latency at night' \\
\hline \multicolumn{3}{|l|}{ in-car } \\
\hline & \multirow[t]{2}{*}{$\mathrm{HMl}$} & $\begin{array}{l}\text { 'drive in a rental car with a lane departure warning system that } \\
\text { constantly warned me in a roadwork section' }\end{array}$ \\
\hline & & 'infotainment-system hangs while driving' \\
\hline & \multirow[t]{2}{*}{ Social environment } & 'co-driver constantly instructs me while driving' \\
\hline & & 'co-driver criticizes my driving mode' \\
\hline & \multirow[t]{2}{*}{ Technical defect } & 'malfunctions of the car' \\
\hline & & 'car didn't recognize the car key' \\
\hline & \multirow[t]{2}{*}{ Wrong information about traffic } & 'obsolete traffic news' \\
\hline & & 'suddenly blocked road' \\
\hline \multicolumn{3}{|l|}{ others } \\
\hline & & 'bad roads (potholes)' \\
\hline & & 'too expensive fuel' \\
\hline \multicolumn{3}{|c|}{ self-inflicted } \\
\hline & & 'got caught in a speed trap' \\
\hline & & 'got lost while driving' \\
\hline \multicolumn{3}{|l|}{ weather } \\
\hline & & 'bad view and difficult driving conditions' \\
\hline & & 'too much heat in the car' \\
\hline
\end{tabular}

\subsection{Implications}

The findings of the current research help to determine what information a frustration-aware assistant needs to know about the driver's context. With increasing availability of sensors in the vehicle, information coming from these can be used not only for recognition of frustration, but also its reasons. Based on the current study, the development of a frustration-aware system can be enriched by 1) knowledge about where to gather information regarding causes of driver frustration and 2) likelihoods of these causes. In combination with the information of measured frustration level, the system can offer help or mitigation methods tailored towards the specific situation.

\subsection{Limitations}

The generalizability of this study is subject to limitations. First, the diary study was distributed the 
Table 3 Examples for mentioned coping strategies

\begin{tabular}{|c|c|c|}
\hline Category & Subcategory & Example \\
\hline \multicolumn{3}{|c|}{ Attentional deployment } \\
\hline & \multirow[t]{2}{*}{ Distraction by media } & 'turn on music' \\
\hline & & 'listen to a podcast' \\
\hline & \multirow[t]{2}{*}{ Think about something else } & 'count to ten' \\
\hline & & 'try to enjoy the landscape' \\
\hline & \multirow[t]{2}{*}{ Distraction by others } & 'distraction through talking to someone' \\
\hline & & 'talk to co-driver (to distract myself)' \\
\hline \multicolumn{3}{|c|}{ Response modulation } \\
\hline & \multirow[t]{2}{*}{ Curse } & 'curse once and call the other an idiot, after that I'm relaxed' \\
\hline & & 'yell out of the window' \\
\hline & \multirow[t]{2}{*}{ Breathing/Relaxing } & 'massage my earlobes' \\
\hline & & 'taking a deep breath' \\
\hline & Smoke & 'smoked a cigarette' \\
\hline \multicolumn{3}{|c|}{ Cognitive change } \\
\hline & \multirow[t]{2}{*}{ Think differently about situation } & 'I took a step back in thought to get an overview' \\
\hline & & 'remind myself that coming home safe is more important than this takeover \\
\hline & \multirow[t]{2}{*}{ Accept situation } & 'see the situation more relaxed' \\
\hline & & 'I decided to wait' \\
\hline & \multirow[t]{2}{*}{ Talk to someone about situation } & 'I talked to my co-driver about the situation' \\
\hline & & 'talk about the situation with a friend on the phone' \\
\hline & \multirow[t]{2}{*}{ Change aims } & 'communicate that I will be too late' \\
\hline & & 'set a new time frame' \\
\hline \multicolumn{3}{|c|}{ Situation modification } \\
\hline & \multirow[t]{2}{*}{ Adapt own driving style } & 'switch on ACC to 80 (instead of the 100 that is allowed) if streets are crowded' \\
\hline & & 'drive slowly' \\
\hline & \multirow[t]{2}{*}{ Look for solution } & 'looked for a solution of the problem' \\
\hline & & 'ask an expert for help' \\
\hline & \multirow[t]{2}{*}{ Leave situation / take a break } & 'look for an alternative route' \\
\hline & & 'took a break' \\
\hline \multicolumn{3}{|c|}{ Situation selection } \\
\hline & \multirow[t]{2}{*}{ Prevention strategies } & 'leave my house on time' \\
\hline & & 'avoid places that repeatedly lead to frustration' \\
\hline
\end{tabular}

among authors' networks. This might have led to a biased group of participants. Second, a diary study during a longer term than one week might show different results. It might be interesting to repeat the study with a larger subject number. Third, data was acquired only during manual drives. When planning to use frustration-aware systems in automated driving, validation of the presented study results is necessary. Currently, this is a challenging task considering the spread of automated vehicles. Last, diary studies and focus groups acquire data by asking participants about their emotion. The answers can be dependent on factors other than the primary cause for frustration (for example, higher frustration if previous events were frustrating that day). Also, reports on frustration given in retrospective (after each ride) might differ from immediate reactions.

\section{Conclusion and outlook}

The results of this study indicate that reasons for experiencing frustration in driving are related to traffic (construction sites, dense traffic, finding parking, red 


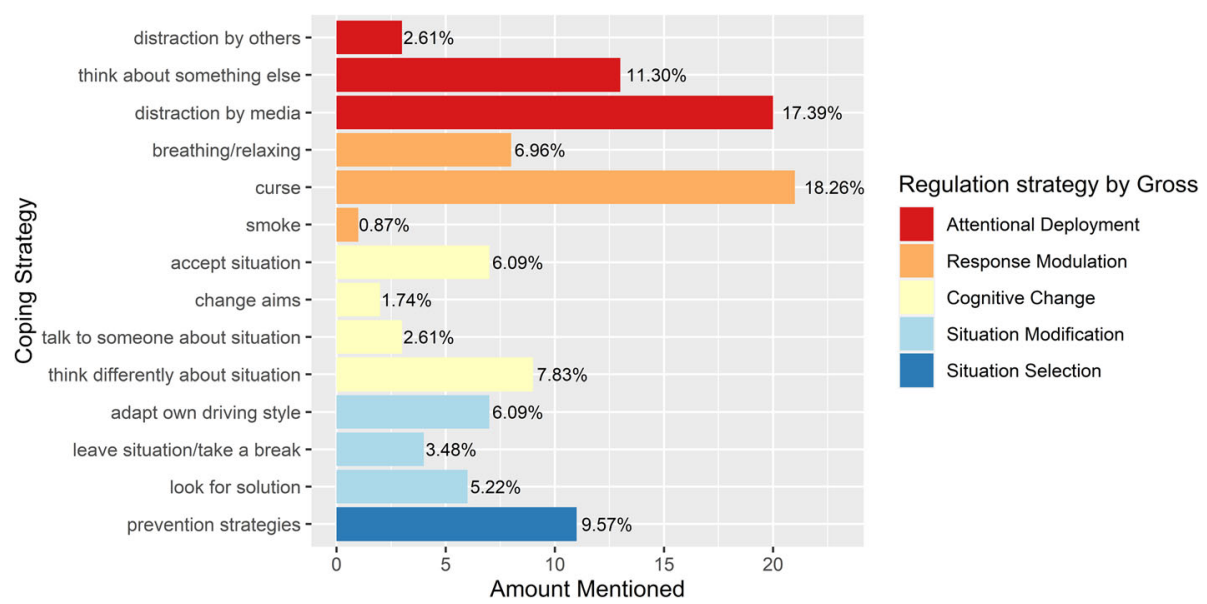

Fig. 10 Coping methods and the amount that they were mentioned

lights, slow vehicles, unclear traffic management, unnecessary traffic rules), in-car causes (events before the start of ride, Human-Machine-Interface, social environment, technical defects, wrong information about traffic), self-inflicted causes and weather conditions. The reasons most feasible to target are probably the ones in the in-car category. By recognition of the frustration's time of occurrence combined with tracking the driver's current focus of attention (e.g., by eye tracking), the cause for frustration could, e.g., be differentiated between events before the start of drive (= frustration is recognized right when the passenger gets into the car) and Human-MachineInterface (= frustration occurs while driver interacts with Human-Machine-Interface). According to the reasons of frustration, a frustration-aware system could offer help through the personal assistant or the Human-Machine-
Interface, and algorithms could be trained towards personal preferences of the user. This help could be inspired by the coping strategy results: finding a solution is the most helpful option, but if that is not possible other ways of mitigating frustration are distraction by others or media or thinking about something else, amongst others. To sum up, this study helped to shed light on reasons for frustration and coping strategies employed by vehicle users. Further studies are needed to verify the research presented here, including hypothesis-based experiments that, e.g., could test for differences between different user groups (for example by age, driving experience, or cultural differences). A future questionnaire could additionally ask participants whether they felt like they were driving differently due to frustration, e.g., unsafely in terms of speeding or decreased time headways. Also, the format of a mobile

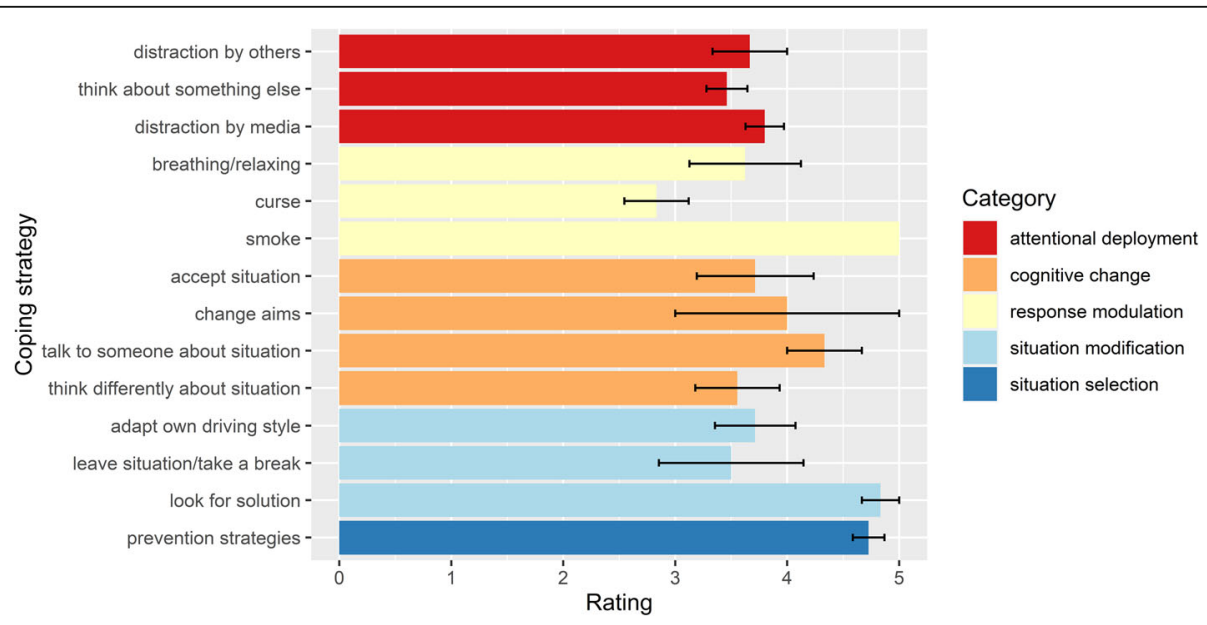

Fig. 11 Rating of helpfulness of coping strategies. Error bars indicate standard error of the mean 
application could facilitate the conduct of the study with a larger number of participants or over a longer time period (e.g. by sending regular reminders). Future research aiming at the design of frustration-aware in-vehicle assistants could build on the knowledge presented here to improve the detection of causes for frustration and the design of optimal coping strategies.

\section{Supplementary information}

Supplementary information accompanies this paper at https://doi.org/10. 1186/s12544-020-00441-7.

\section{Additional file 1}

\section{Acknowledgements}

The authors gratefully acknowledge the support of Meike Kühne, Sarah Klages and Alexander Behrens during data collection and categorization.

\section{Author's contributions}

Diary study: EB conceived, designed, acquired, analysed and interpreted the data, all with supervision of KI. UD helped with conception, design and interpretation of the data. Focus Group study: MO conceived, designed and acquired the data in consultation with EB and KI. EB did data analysis and interpretation with help of $\mathrm{MO}$ und $\mathrm{Kl}$. JM helped with conception and interpretation of the work of both studies. EB drafted the paper and $\mathrm{Kl}, \mathrm{MO}$ and JM substantively revised it. All authors read and approved the final manuscript.

\section{Funding}

This work was partly supported by the project F-RELACS which receives funding from the German Federal Ministry of Education and Science in the program KMU-innovativ under the grant 16SV7930. Open access funding provided by Projekt DEAL.

\section{Availability of data and materials}

The dataset supporting the conclusions of this article is included within the article and its additional file.

\section{Competing interests}

There are no competing interests.

Received: 12 May 2020 Accepted: 17 August 2020

Published online: 22 September 2020

\section{References}

1. Aslam, S., Verhoeven, G., Gouweleeuw, K., \& Zwart, N. (2019). Classification of disappointment and frustration elicited by human-computer interaction: Towards affective $\mathrm{HCl}$.

2. Berg, J., Levin, L., Abramsson, M., \& Hagberg, J.-E. (2015). "I want complete freedom": Car use and everyday mobility among the newly retired. European transport research review, 7, 31

3. Berkowitz, L. (1990). On the formation and regulation of anger and aggression: A cognitive-neoassociationistic analysis. American Psychologist, 45, 494.

4. Deffenbacher, J. L., Deffenbacher, D. M., Lynch, R. S., \& Richards, T. L. (2003). Anger, aggression, and risky behavior: A comparison of high and low anger drivers. Behaviour research and therapy, 41, 701-718.

5. Dollard, J., Miller, N. E., Doob, L. W., Mowrer, O. H., \& Sears, R. R. (1939). Frustration and aggression.

6. Eyben, F., Wöllmer, M., Poitschke, T., Schuller, B., Blaschke, C., Färber, B., et al. (2010). Emotion on the road-Necessity, acceptance, and feasibility of affective computing in the car. Advances in Human-Computer Interaction, (p. 2010).

7. Folkman, S., \& Lazarus, R. S. (1990). Coping and emotion. Psychological and biological approaches to emotion, (pp. 313-332).

8. Geis, I. (2019). Foreign countries, foreign customs: An analysis of shortdistance mobility of new immigrants in the Rhine-Main region in Germany. European transport research review, 11, 23.
9. Gross, J. J. (1998). The emerging field of emotion regulation: An integrative review. Review of general psychology, 2, 271-299.

10. Huemer, A. K., Oehl, M., \& Brandenburg, S. (2018). Influences on anger in German urban cyclists. Transportation Research Part F: traffic psychology and behaviour, 58, 969-979.

11. Ihme, K., Unni, A., Zhang, M., Rieger, J. W., \& Jipp, M. (2018). Recognizing Frustration of Drivers From Face Video Recordings and Brain Activation Measurements With Functional Near-Infrared Spectroscopy. Frontiers in human neuroscience, 12, 327

12. Jeon, M., Walker, B. N., \& Yim, J.-B. (2014). Effects of specific emotions on subjective judgment, driving performance, and perceived workload. Transportation Research Part F: traffic psychology and behaviour, 24, 197-209.

13. Johnson, M., \& McKnight, S. (2009). Warning drivers about potential congestion as a means to reduce frustration-driven aggressive driving. Traffic Injury Prevention, 10, 354-360.

14. Lazar, J., Jones, A., Hackley, M., \& Shneiderman, B. (2005). Severity and impact of computer user frustration: A comparison of student and workplace users. Interacting with Computers, 18, 187-207.

15. Lazarus, R. S. (1991). Emotion and adaptation. Oxford University Press on Demand.

16. Lee, Y.-C. (2010). Measuring drivers' frustration in a driving simulator, (p. 19).

17. Li, S., Zhang, T., Liu, N., Zhang, W., Tao, D., \& Wang, Z. (2020). Drivers' attitudes, preference, and acceptance of in-vehicle anger intervention systems and their relationships to demographic and personality characteristics. International Journal of Industrial Ergonomics, 75, 102899.

18. Löcken, A., Ihme, K., and Unni, A., eds (2017). Towards designing affect-aware Systems for Mitigating the effects of in-vehicle frustration. ACM.

19. Malta, L., Miyajima, C., Kitaoka, N., \& Takeda, K. (2011). Analysis of real-world driver's frustration. IEEE Transactions on Intelligent Transportation Systems, 12, 109-118.

20. Mikolajczak, M., Nelis, D., Hansenne, M., \& Quoidbach, J. (2008). If you can regulate sadness, you can probably regulate shame: Associations between trait emotional intelligence, emotion regulation and coping efficiency across discrete emotions. Personality and Individual Differences, 44, 13561368.

21. Miller, N. E. (1941). I. The frustration-aggression hypothesis. Psychological review, 48, 337.

22. Oehl, M., Ihme, K., Drewitz, U., Pape, A.-A., Cornelsen, S., and Schramm, M., eds (2019). Towards a frustration-aware assistant for increased in-vehicle UX: F-RELACS. ACM.

23. Parker, A., \& Tritter, J. (2006). Focus group method and methodology: Current practice and recent debate. International Journal of Research \& Method in Education, 29, 23-37.

24. Raux, C., Ma, T.-Y., \& Cornelis, E. (2016). Variability in daily activity-trave patterns: the case of a one-week travel diary. European Transport Research Review, 8, 26.

25. Shinar, D. (1998). Aggressive driving: The contribution of the drivers and the situation. Transportation Research Part F: traffic psychology and behaviour, 1, 137-160.

26. Team, R. C. (2019). R Core Team (2019). R: A language and environment for statistical computing. In R Found. Stat. Comput. Vienna, Austria URL http:// www.R-project. org/., page R Foundation for Statistical Computing.

27. Underwood, G., Chapman, P., Wright, S., \& Crundall, D. (1999). Anger while driving. Transportation Research Part F: traffic psychology and behaviour, 2, $55-68$.

28. Wirtz, M. A., \& Strohmer, J. (2017). Dorsch-Lexikon der Psychologie. 18. überarbeitete Auflage. Bern: Hogrefe.

29. Zepf, S., Dittrich, M., Hernandez, J., and Schmitt, A., eds (2019). Towards empathetic Car interfaces: Emotional triggers while driving. ACM.

\section{Publisher's Note}

Springer Nature remains neutral with regard to jurisdictional claims in published maps and institutional affiliations. 